\title{
Transanal endoscopic microsurgery after the attempt of endoscopic removal of rectal polyps
}

\author{
Monica Ortenzi ${ }^{1}$ [ $\cdot$ Alberto Arezzo ${ }^{2} \cdot$ Roberto Ghiselli $^{1} \cdot$ Marco Ettore Allaix ${ }^{2} \cdot$ Mario Guerrieri $^{1} \cdot$ Mario Morino $^{2}$
}

Received: 16 November 2021 / Accepted: 18 February 2022 / Published online: 4 March 2022

(c) The Author(s) 2022, corrected publication 2022

The incidence of rectal polyps has steadily increased in recent decades and will continue to rise. [1] The introduction of endoscopic screening programs has probably contributed to the improved detection of rectal polyps and early malignant lesions $[2,3]$. With the aim to reduce morbidity and mortality of rectal surgery, in 1983, Gerhard Buess introduced Transanal Endoscopic Microsurgery (TEM) [4]. He conceived a novel endoscopic technology to facilitate the excision of rectal polyps through the anus [5]. This revolutionary technique enabled superficial or full-thickness excision of large adenomatous lesions. It soon became apparent that indications to TEM could be successfully extended to early malignant polyps $[6,7]$.

However, in the late nineties, endoscopy was advocated as a diagnostic technique and a therapeutic method. First, large piecemeal snare ablations were reported. Then, the use of endoscopic electrosurgical knives made it possible to achieve en bloc resection, known as Endoscopic Submucosal Dissection (ESD) [8-11]. The sharp increase in endoscopic resection of rectal polyps made the indications for TEM questioned [12].

This unresolved debate confuses the choice of the optimal treatment for complex rectal polyps. Concerns mainly arise where there is uncertainty around early malignancy or where complete resection of an adenomatous polyp is not obtained following endoscopic attempts [13-15]. Accurate prognostic information is not always available after endoscopic removal, mainly when the specimen is fragmented. [16] Additionally, fibrotic tissue growth at the polypectomy site could invalidate the already sub-optimal accuracy of pre-operative imaging techniques. Therefore, endoscopic

Monica Ortenzi

monica.ortenzi@gmail.com

1 Department of General and Emergency Surgery, Polytechnic University of Marche, Via Conca 1, 60126 Ancona, Italy

2 Department of Surgical Sciences, University of Torino, Turin, Italy ultrasound and/or Magnetic Resonance Imaging staging are often misleading [17]. The indication to resect the site of a previous endoscopic resection with a full-thickness technique has been recommended in cases of unexpected malignancy. However, the overall benefit remains unclear $[13,18]$.

This study aims to evaluate the outcomes of TEM following endoscopic resection of rectal polyps performed at two different centres, assess the value of further local excision, and identify features that may contribute to the decisionmaking process.

\section{Materials and methods}

We merged two prospective databases and searched for all patients who underwent TEM following any endoscopic excision of a rectal polyp. The two databases include all consecutive patients who underwent TEM for any reason at the Department of Surgical Sciences of the University of Torino and the Department of Surgery of the University of Ancona. Altogether they consist of a total of 2520 patients performed between 1993 and June 2020. Databases consisted of Excel format sheets, including patient characteristics, pre-operative work-up, TEM indications, perioperative data, and follow-up until the latest contact. All the procedure were carried out by experienced surgeons with more than 100 procedures performed before the enrolment period.

A full-thickness excision was performed in all cases, and the rectal wall defect closed with an absorbable monofilament running suture secured with silver clips and, more recently, titan clips (Richard Wolf, Knittlingen, Germany). Two different sets were used: one was a dedicated instrumentation with a 12 or $20 \mathrm{~cm}$ modified rectoscope with 3 operative channels (Richard Wolf, Knittlingen, Germany) and 3D dedicated optics, the other a similar device 7 or $15 \mathrm{~cm}$ long (Karl Storz Endoskope, Tuttlingen) with standard 2D vision, both $4 \mathrm{~cm}$ in diameter. Both were fixed in position with a Martin arm, a three-elbowed device attached 
to the operating table. The traditional TEM curved instrumentation [19] or laparoscopic devices were used according to the preference of the surgeon.

We analysed the patients' characteristics, pre-operative work-up, the type of surgery performed, the pre-operative data, the definitive histology, the intra-operative and postoperative complications and finally, the recurrence rate after treatment. The paper is written according to the STROCCS 2021 guidelines [20].

\section{Inclusion criteria}

We enrolled all consecutive patients undergoing TEM after partial or complete endoscopic resection of a rectal polyp between January 2011 and June 2020. Indications for TEM were recorded as well as the number of previous endoscopic removal attempts. Common indications for TEM were the persistence of visible residual disease, both benign and malignant, and the histology of malignancy on the specimen even of an apparent complete endoscopic excision.

\section{Work-up}

The need for radical rescue surgery was established based on post-TEM histology. All the patients fit for surgery and resulting affected by an early rectal cancer with unfavourable characteristics, or a locally advanced rectal cancer was considered eligible for radical abdominal surgery.

If the residual neoplasms or post-EMR scars were not easily detected at the rigid proctoscopy performed prior to TEM to correctly locate the lesions, patients underwent flexible sigmoidoscopy and tattooing before surgery.

TEM excision was considered curative in case of no residual malignant disease, excision of residual benign polyps or up to pT1sm1 cancers. In benign histology, these patients underwent post-operative follow-up every 3 months for 2 years, with clinical examination, digital rectal examination, flexible rectosigmoid endoscopy. In malignancy, follow-up was prolonged till 5 years after surgery, with 6 months intervals and included monitoring neoplastic markers and imaging for possible metastases. Patients with a follow-up shorter than 6 months were excluded. The analysis was conducted according to the intention-to-treat principle.

\section{Outcomes}

The primary outcome was to assess the rate of curative TEM procedures avoiding the need for radical surgery. Secondary outcomes were morbidity at 30 days after TEM, rate of rescue surgery, recurrence rate, type of recurrence, overall survival and disease-free survival. Depending on the indication for TEM, results were analysed in three groups: (a) Complete endoscopic excision of unexpected cancers, (b) incomplete endoscopic excision of unexpected cancers, (c) incomplete endoscopic excision of adenomas.

\section{Statistical analysis}

We summarised qualitative variables as absolute and percentage frequencies in brackets. We used Fisher's exact test to evaluate differences between categorical variables. We reported the descriptive data as median with interquartile range (IQR) and Wilcoxon rank-sum test to compare them. Cox proportional-hazards regression was used to assess outcome and for univariate analysis. Univariate analysis was used to identify risk factors for incomplete endoscopic excision and recurrence. Results were expressed as odds ratios (OR) and 95\% Confidence Intervals (95\% CI).

A multivariate analysis Cox regression analysis was used to evaluate the prognostic role of clinical and surgical variables in recurrence probability. Hazard ratios (HR) and 95\% Confidence Intervals (95\% CI) were also calculated.

Gender, age (dichotomized at 60 years), distance from anal verge (dichotomized at $5 \mathrm{~cm}$ ), tumour size before endoscopic removal (dichotomized at $2 \mathrm{~cm}$ ), and tumour histological characteristics (benign, pT stage, differentiation, Lymph vascular invasion, budding) were considered as independent factors. The factors used in regression analyses were set a priori.

Kaplan-Meier estimates were obtained for local recurrence-free, disease-free and overall survival. Patients without recurrence were censored at the date of last follow-up or death.

The statistical significance was assessed at a level of probability of 0.05 . All statistical analyses were performed using MedCalc Statistical Software (MedCalc Software bv, Ostend, Belgium).

\section{Results}

We included a total of 150 patients who underwent TEM between January 2011 and June 2020. There were 103 males and 47 females (Table 1).

Most rectal lesions were removed with a piecemeal endoscopic mucosal resection (p-EMR) $(n=133,88.7 \%)$ and by ESD in the remaining 17 patients $(11.3 \%)$. The median diameter of endoscopically excised lesions was $3 \mathrm{~cm}(\mathrm{IQR}=2-4 \mathrm{~cm})$. The median distance of the lesions from the anal verge was $8 \mathrm{~cm}(I Q R=6-11 \mathrm{~cm})$. Rectal lesions with size $>2 \mathrm{~cm}$ that underwent incomplete EMR were significantly larger than polyps that were excised entirely (median size 3 vs $2 \mathrm{~cm}$, respectively, $p=0.001$ ). All other considered variables were comparable (Table 1). The indication for TEM was primarily to obtain a wider 
Table 1 Patients' demographic and clinical characteristics

\begin{tabular}{|c|c|c|c|c|}
\hline Variables & $\begin{array}{l}\text { c-EMR } \\
n=77\end{array}$ & $\begin{array}{l}\text { i-EMR } \\
n=73\end{array}$ & $p$ & Total $(n=150)$ \\
\hline Sex $[$ Males, $n(\%)]$ & $55(71.4)$ & $48(65.7)$ & $0.485^{*}$ & $103(68.6)$ \\
\hline Age [years, median (IRQ)] & $68(61-76)$ & $69(62-75)$ & $0.749 * *$ & $68.5(62-76)$ \\
\hline Size before endoscopy [cm, median IRQ)] & $2(1.5-3)$ & $3(2-4.2)$ & $<0.001 * *$ & $3(2-4)$ \\
\hline Size $>2 \mathrm{~cm}[n(\%)]$ & $46(59.7)$ & $49(67.1)$ & $0.008^{*}$ & $95(63.3)$ \\
\hline Distance from anal verge $[\mathrm{cm}$, median IRQ)] & $7(6-11)$ & $9(5-10.2)$ & $0.709 * *$ & $8(6-11)$ \\
\hline \multicolumn{5}{|l|}{ Site of the lesion $[n(\%)]$} \\
\hline Anterior & $16(20.8)$ & $20(27.4)$ & $0.444^{*}$ & $36(32)$ \\
\hline Right quadrant & $16(20.8)$ & $11(15)$ & $0.401 *$ & $27(18.7)$ \\
\hline Left quadrant & $19(24.7)$ & $20(27.4)$ & $0.714^{*}$ & $39(26)$ \\
\hline Posterior & $26(33.8)$ & $18(24.6)$ & $0.726^{*}$ & $48(32)$ \\
\hline \multicolumn{5}{|l|}{$\mathrm{cT}$} \\
\hline $\mathrm{cT} 1$ & $45(58.4)$ & $25(34.2)$ & $0.003^{*}$ & $70(46.7)$ \\
\hline cT2 & $8(10.4)$ & 0 & $0.006^{*}$ & $8(5.3)$ \\
\hline Surgical time [minutes, median (IRQ)] & $45(35-60)$ & $45(35-71.2)$ & 0.224 & $45(35-65)$ \\
\hline Difficulty in dissection & $3(3.9)$ & $4(5.2)$ & 0.713 & $7(4.7)$ \\
\hline Post-operative complications $[n(\%)]$ & $7(9.1)$ & $11(15.1)$ & $0.318^{*}$ & $18(12)$ \\
\hline Dindo Clavien I $[n(\%)]$ & $1(1.3)$ & $7(9.6)$ & $0.030 *$ & $8(5.3)$ \\
\hline Fever & $1(1.3)$ & $4(5.5)$ & & \\
\hline Bleeding & 0 & $3(4.1)$ & & \\
\hline Dindo Clavien II [ $n(\%)]$ & $4(5.2)$ & $2(2.7)$ & $0.681^{*}$ & $6(4)$ \\
\hline Bleeding & $4(5.2)$ & $2(2.7)$ & & \\
\hline Dindo Clavien IIIa [ $n(\%)]$ & $2(2.6)$ & $2(2.7)$ & ns* & $4(2)$ \\
\hline Suture dehiscence & $1(1.3)$ & $1(1.4)$ & & \\
\hline Bleeding & $1(1.3)$ & $1(1.4)$ & / & \\
\hline Length of hospital stay [days, median (IRQ)] & $3(2.5-4)$ & $3(2-4)$ & $0.945^{* *}$ & $3(2-4)$ \\
\hline Readmissions $[n(\%)]$ & 0 & $2(3.4)$ & $0.235^{*}$ & 2() \\
\hline Rescue surgery $[n(\%)]$ & $5(6.5)$ & $3(4.1)$ & $0.719^{*}$ & $8(5.3)$ \\
\hline Recurrences & $4(5.2)$ & $4(5.5)$ & ns* & $(5.3)$ \\
\hline Local & $3(3.9)$ & $4(5.5)$ & $0.713^{*}$ & $7(4.7)$ \\
\hline Distant & $1(1.3)$ & 0 & I & $1(0.7)$ \\
\hline
\end{tabular}

IRQ: 1 st-3rd quartiles

$c$-EMR complete EMR, $i$-EMR incomplete EMR

*Fisher exact test

**Wilcoxon rank-sum test

local excision in cases of unexpected cancerous polyp observed on definitive histology following polypectomy $(101,67.3 \%)$ (Table 1).

In one case, the defect was left open due to the presence of an abscess following the endoscopic procedure. In 4 patients (2.6\%), accidental opening of the peritoneum was observed during surgery. This was sutured transanally in all cases without sequelae. No intraoperative complications were reported. However, in 7 (4.7\%) cases, an increased difficulty, defined as increased resistance to tissue dissection due to fibrosis, was reported. The median operative time was $45 \mathrm{~min}$ (IQR = 35-65 $\mathrm{min}$, ) and it did not statistically differ whether the lesion was excised entirely or not before TEM $(p=0.224)($ Table 1$)$.
Post-operative complications occurred in 18 patients (12\%): 8 type I (5.3\%), 6 type 2 (4\%), 4 type 3 a (2.7\%) according to Dindo Clavien classification. The median length of hospital stay was 3 days (IQR $=2-4$ days). Two patients $(1.3 \%)$ were readmitted within 30 days of discharge, 1 for rectal bleeding and 1 for hyperthermia (Table 1).

\section{Results by pathology and staging}

\section{Complete endoscopic excision of unexpected cancers}

Seventy-seven individuals received TEM after complete endoscopic excision of a polyp but unexpected harbour foci of malignant cells. A persistence of lesions in the form 
of dysplastic tissue was detected in $16(20.8 \%)$ cases and of cancerous lesions in 12 (15.6\%) (Fig. 1). In all cases, the lesions were defined as completely excised after TEM. No recurrences were observed after local excision of the residual dysplastic lesions. Pathology revealed pT1sm1 adenocarcinoma in 2 patients while showed a pT2 and pT3 infiltration of the rectal wall in $9(10.4 \%)$ and $1(8.3 \%)$ cases, respectively. Four T2 and the T3 adenocarcinomas underwent rescue Total Mesorectal Excision (TME), while the remaining refused or were deemed unfit for major surgery. The presence of fibrotic tissue was confirmed in 49 $(63.6 \%)$ patients.
Fig. 1 Results according to the completeness of endoscopic excision
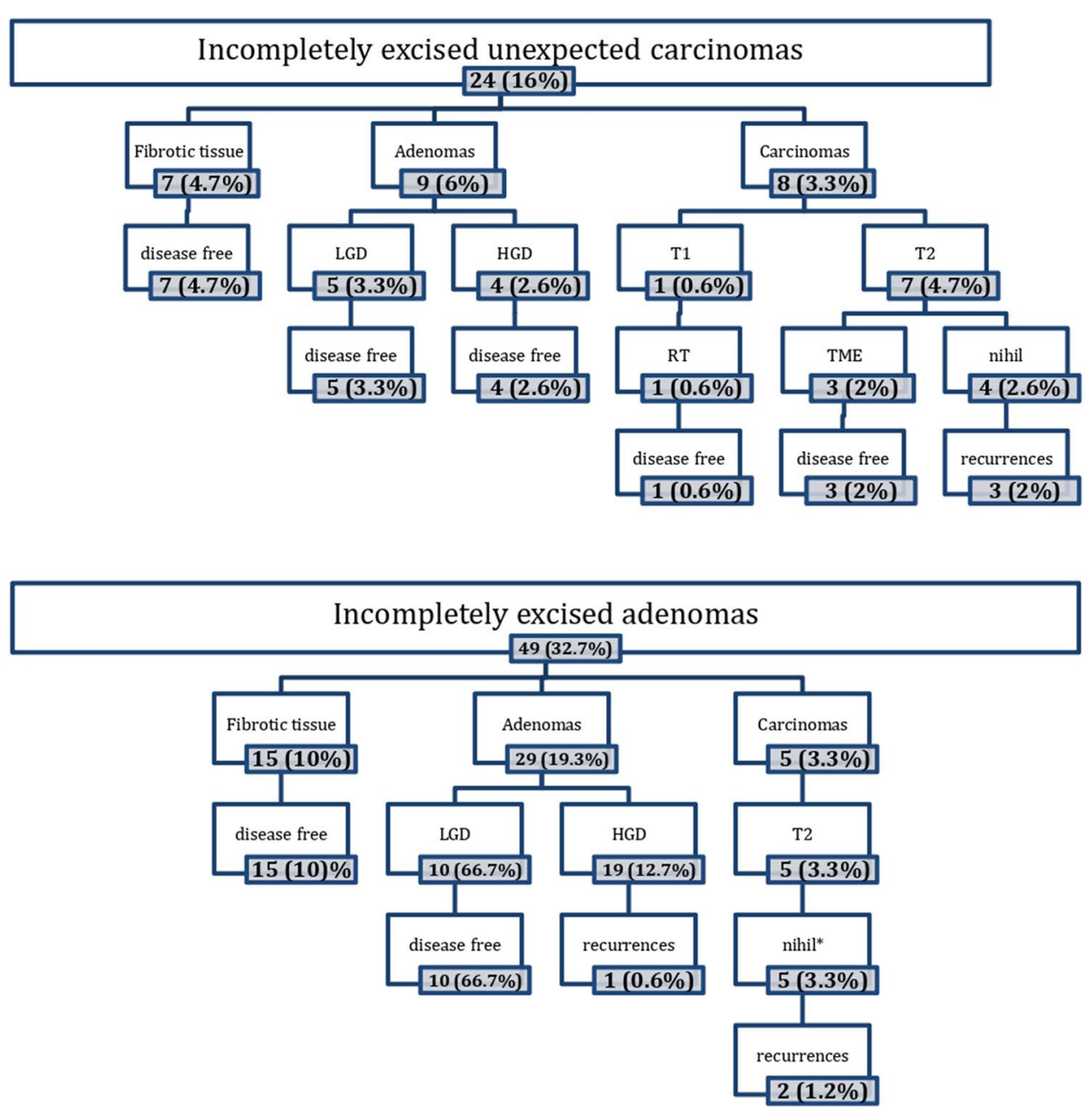

*1 lost at follow up

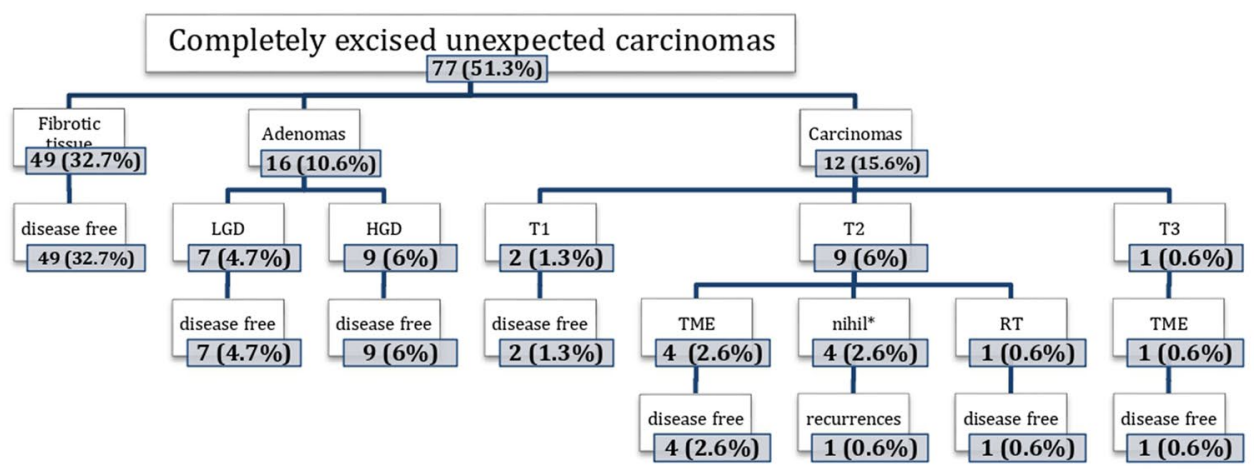

*1 lost at follow up 


\section{Incomplete endoscopic excision of unexpected cancers}

Twenty-four individuals underwent TEM because of visible residual tissue after one or several attempts of endoscopic removal, with a histological report revealing the presence of unexpected cancerous cells (Table 2). The histological examination of the TEM specimen showed persistent cancer cells in $8(33.3 \%)$ residual lesions, staged as pT $1 \mathrm{sm} 2$ in 1 case and as pT2 in the remaining 7 cases, respectively (Fig. 2). The T1 adenocarcinoma was further treated with adjuvant radiotherapy after TEM and showed no recurrence at 23.4 months. Of the 7 patients diagnosed with pT2 cancer, 3 received a completion TME and were all free of disease at 9, 15 and 43 months, respectively. In contrast, 4 did not receive further treatment despite indications due to patients' refusal or judged unfit for major surgery. Three of them experienced local recurrences at 6, 10 and 12 months, while the fourth is free of disease at 18 months. Nine patients (37.5\%) had residual dysplastic
Table 2 Results according to histology

\begin{tabular}{lccc}
\hline Variables & Total $(n=150)$ & $\begin{array}{l}\text { Post EMR malignant } \\
\text { disease }\end{array}$ & $\begin{array}{l}\text { Post EMR } \\
\text { benign } \\
\text { disease } \\
n=49\end{array}$ \\
& & $n=101$ & \\
\hline Gender $[n(\%)]$ & $103(68.7)$ & $70(69.3)$ & $33(67.3)$ \\
Male & $47(31.3)$ & $31(30.7)$ & $16(32.6)$ \\
Female & $68.5(62-76)$ & $68(61.5-76)$ & $72(61.7-76)$ \\
Age [years, median (IQR)] & $7(6-11)$ & $7(6-10)$ & \\
Distance from the anal verge [cm, & & & $49(100)$ \\
median (IQR)] & $73(48.7)$ & $24(23.8)$ & 0 \\
Macroscopic residual disease $[n(\%)]$ & $77(51.3)$ & $77(76.2)$ & $15(30.6)$ \\
Yes & & & $29(59.2)$ \\
No & $71(47.3)$ & $56(55.4)$ & $10(20.4)$ \\
Post TEM histology & $54(36)$ & $25(24.7)$ & $19(38.8)$ \\
Fibrosis & $22(14.7)$ & $12(11.9)$ & $5(10.2)$ \\
Adenomas $[n(\%)]$ & $32(21.3)$ & $13(12.8)$ & 0 \\
Low grade $[n(\%)]$ & $25(16.7)$ & $20(19.8)$ & $5(10.2)$ \\
High-grade dysplasia $[n(\%)]$ & $4(2.7)$ & $4(3.9)$ & 0 \\
Carcinomas $(\mathrm{T})[n(\%)]$ & $20(13.3)$ & $15(14.8)$ & $1(0.99)$ \\
T1 $[n(\%)]$ & $1(0.7)$ & & \\
T2 $[n(\%)]$ & & & \\
T3 $[n(\%)]$ & & & \\
\hline
\end{tabular}

IQR: 1st-3rd quartiles range
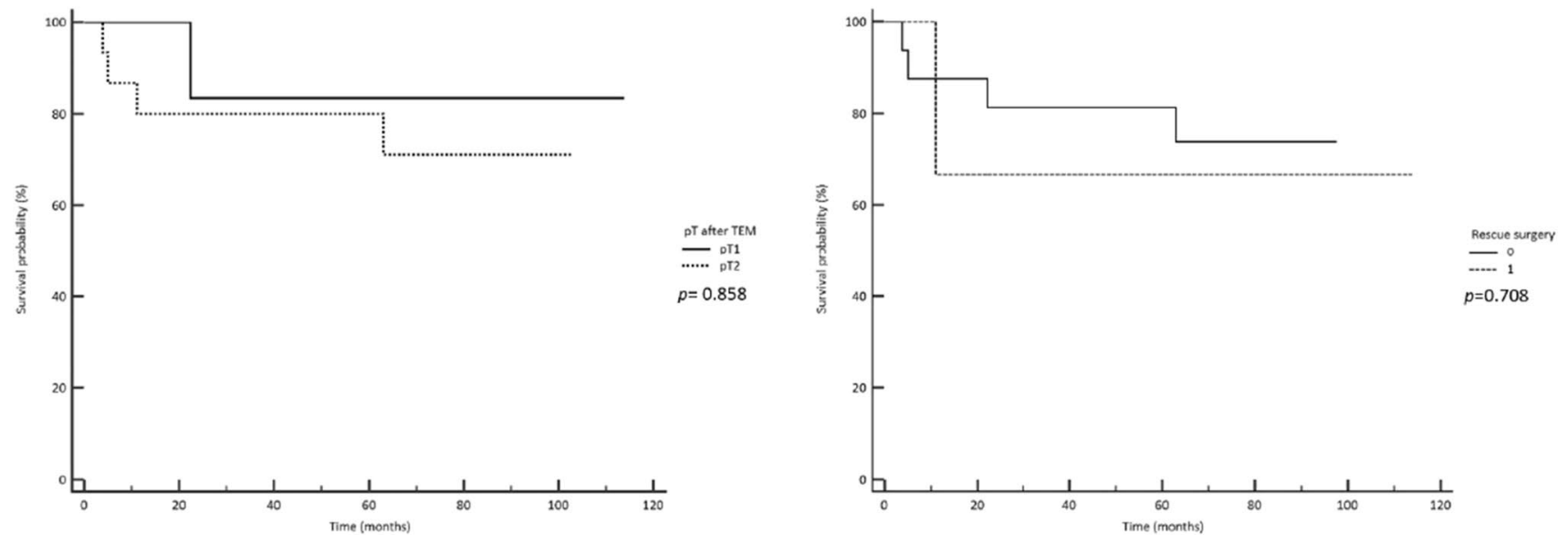

Fig. 2 Disease-free survival probability according to pT stage after TEM and rescue surgery 
tissue. None of these patients had a recurrence. In 7 (29.2\%) patients, no residual disease was found.

\section{Incomplete endoscopic excisions of adenomas}

Forty-nine individuals received TEM because of visible residual tissue after one or several attempts of endoscopic removal, with a histological report revealing the presence of adenomatous cells (Table 2). After local excision by TEM, definitive histology showed a pT2 residual adenocarcinoma in $5(10.2 \%$ ) individuals (Fig. 2). None of these underwent rescue TME, despite indication, due to patients' refusal or because judged unfit for major surgery. In 29 (59.2\%) patients, a residual adenomatous lesion was found. Of these, 1 of 19 patients with a high-grade dysplastic polyp recurred at 8.7 months after local excision, while there was no recurrence in the 10 patients with a low-grade dysplastic adenoma. Only fibrotic tissue was found in the remaining $15(30.6 \%)$ patients.

\section{Follow-up of local excision by TEM of unexpected cancer}

Overall, 25 patients were diagnosed with residual or recurrent cancer on the TEM specimen. Three were diagnosed with pT 1 cancer, 21 with a pT2 and 1 with a pT3, respectively. With a minimum follow-up of 6 months, the disease-free survival (DFS) was 89.9\% (95\% CI 78.4-99.4, $p=0.319)$. Rescue radical surgery was performed in
8 patients (5.3\%) (Table 1) and consisted of TME in 6 cases, TransAnal TME (TaTME) in 1 case and Abdominal Perineal Resection (APR) in 1 case. Definitive histology showed remnant disease in 5 cases, staged pT3N0 in 3, pT2 N2a in 1, and pT0 N1 in 1 case, respectively. None of them demonstrated recurrent disease at a minimum follow-up of 7 months (median 78 months, IQR $=54-101$ months). No recurrence was observed among patients staged as pT1 cancer. Thirteen of the 21 patients diagnosed with pT2 cancer after TEM did not undergo rescue surgery, either due to refusal or judged unfit. While no recurrence was observed among those who underwent further radical surgery, an overall recurrence rate of $46.1 \%$ was reported in the rest of the patients (6/13). The relapse of neoplastic tissue occurred in 1 case as dysplasia, which was further treated with TEM, and in 6 patients as carcinoma treated in 2 cases with TME, in 1 case with APR, in 1 further case TEM and 1 case with palliative radiotherapy (Table 3) while a seventh patient refused further treatment. One patient, after rescue surgery by APR, developed pulmonary metastases. The univariate analysis for risk of recurrence (Table 4) showed no statistical significance for gender and distance from the anal verge. Size before endoscopy and malignant histology before TEM were demonstrated to be significant risk factors for recurrence. The multivariate analysis for risk of recurrence (Table 5) indicated size before endoscopy as an independent predictor of recurrence (Fig. 2).

Table 3 Pattern of recurrence

\begin{tabular}{|c|c|c|c|c|c|c|}
\hline Patients & Post EMR histology & Indication to TEM & $\begin{array}{l}\text { Post TEM } \\
\text { histology }\end{array}$ & Time to recurrence & $\begin{array}{l}\text { Management of recur- } \\
\text { rence }\end{array}$ & Follow-up \\
\hline 1 & Adenocarcinoma & $\begin{array}{l}\text { Radicalization of com- } \\
\text { plete excision of unex- } \\
\text { pected malignancy }\end{array}$ & pT2 & 8.4 months & TME (pT4b N0) & $\begin{array}{l}\text { Pulmonary metastasis at } \\
34.8 \text { months }\end{array}$ \\
\hline 2 & HGD & $\begin{array}{l}\text { Radicalization of three } \\
\text { previous attempts of } \\
\text { removal }\end{array}$ & pT2 & 5 months & TEM (HGD) & Free of disease \\
\hline 3 & HGD & $\begin{array}{l}\text { Radicalization of incom- } \\
\text { plete excision }\end{array}$ & HGD & 8.7 months & TEM (HGD) & Free of disease \\
\hline 4 & Adenocarcinoma & $\begin{array}{l}\text { Radicalization of com- } \\
\text { plete excision of unex- } \\
\text { pected malignancy }\end{array}$ & pT2 & 23 months & RT & Free of disease \\
\hline 5 & Adenocarcinoma & $\begin{array}{l}\text { Radicalization of incom- } \\
\text { plete excision }\end{array}$ & pT2 & 3.74 months & l & Lost after local recurrence \\
\hline 6 & Adenocarcinoma & $\begin{array}{l}\text { Radicalization of } \\
\text { complete excision of } \\
\text { unexpected malignan- } \\
\text { cies }\end{array}$ & pT2 & 10.4 months & TME (pT2 N0) & Free of disease \\
\hline 7 & Adenocarcinoma & $\begin{array}{l}\text { Radicalization of incom- } \\
\text { plete excision of unex- } \\
\text { pected malignancy }\end{array}$ & pT2 & 3.8 months & APR (pT3 N0) & $\begin{array}{l}\text { Second recurrence at } \\
36 \text { months treated with } \\
\text { RT }\end{array}$ \\
\hline
\end{tabular}

$H G D$ high grade dysplasia, $T M E$ total mesorectal excision, $A P R$ abdominal perineal resection, $C R T$ chemoradiotherapy, $R T$ radiotherapy 
Table 4 Univariate analysis of categorical variables as risk factors of recurrence

\begin{tabular}{lllr}
\hline Variables & OR & $95 \%$ CI & $p$ \\
\hline Gender [Male vs female] & 0.340 & $0.039-2.909$ & 0.324 \\
Age [<60 years vs $\geq 60$ years] & 0.514 & $0.093-2.821$ & 0.464 \\
Distance from anal verge $[<5 \mathrm{~cm} \mathrm{vs} \geq 5 \mathrm{~cm}$ ] & 2.144 & $0.249-18.489$ & 0.450 \\
Size before endoscopy [<2 cm vs $\geq 2 \mathrm{~cm}$ ] & 6.160 & $1.248-30.406$ & 0.037 \\
Endoscopic excision [Complete vs incomplete] & 1.533 & $0.329-7.126$ & 0.583 \\
Histology [Adenoma vs carcinoma] & 17.656 & $0.157-98.739$ & $<0.001$ \\
pT stage [pT1 vs pT2] & 0.615 & $0.043-8.703$ & 0.724 \\
Tumour differentiation [G1 vs G2] & $/$ & $/$ & 0.055 \\
Lymph vascular invasion [LV1 vs LV0] & $/$ & $/$ & 0.302 \\
Tumour budding [Budding+ vs budding-] & $/$ & $/$ & 0.094 \\
\hline
\end{tabular}

Table 5 Factors associated with recurrence on multivariate analysis

\begin{tabular}{lcccc}
\hline & \multicolumn{3}{l}{$95 \% \mathrm{CI}$} & \\
\cline { 2 - 5 } & OR & Lower & Upper & $p^{*}$ \\
\hline Gender [M vs F] & 0.46 & 0.05 & 3.91 & 0.445 \\
Age $>$ 60 vs age $\leq 60$ years & 0.53 & 0.10 & 2.71 & 0.471 \\
Distance from anus (cm) & 0.49 & 0.25 & 17.2 & 0.457 \\
Size before endoscopy $(\mathrm{cm})$ & 1.41 & 0.27 & 7.20 & 0.674 \\
T1 vs T2 & 0.61 & 0.05 & 6.73 & 0.702 \\
\hline
\end{tabular}

*Cox regression model

\section{Discussion}

When introduced in 1983, TEM offered both a minimally invasive technique and a definitive treatment for large rectal polyps. This is because it enabled an en-bloc polyp resection through either a full-thickness or a submucosal rectal wall excision [9-11]. More recently, p-EMR and ESD became increasingly adopted to manage rectal polyps. Consequently, the use of TEM has been questioned and, in some cases, even deemed obsolete. Nevertheless, the optimal management of these polyps remains highly debated for several reasons [18, 21-25]. Not rarely TEM is advocated after incomplete endoscopic resection or the discovery of unexpected cancer.

As always, TEM, even after a previous endoscopic attempt, aims at reducing the need for major surgery (TME or APR), which is burdened with a high rate of complication and impaired quality of life. Some of the observed results were predictable. The short operative time and the low morbidity align with the results obtained when TEM is used as first-line treatment. Similar to standard TEM results are intraoperative and post-operative complications, all minor and manageable with no further intervention.

Other findings were less obvious and deserved discussion. About 1/3 of TEM procedures performed after apparently complete removal of unexpected cancer and 2/3 of those performed after incomplete removal of an unexpected cancer show persistent neoplastic tissue. This is malignant in about $1 / 6$ in the first case and about $1 / 3$ in the second case. Still, TEM showed excellent characteristics to select those patients who deserve rescue surgery, saving the vast majority of patients $(81 / 101,80 \%)$ with no indication based on the pathology examination of the specimen resected by TEM. Moreover, even after incomplete endoscopic excision of a histology proven adenoma, there is a $10 \%$ risk to find malignant tissue at further local excision. Fortunately, in all these cases, TEM has been deemed an appropriate intermediate treatment with this indication.

Correct initial staging is essential to provide a precise indication for radical surgery $[15,26]$. This is very difficult to obtain at first observation of a rectal polyp, with about $20 \%$ overstaging and about $20 \%$ understaging of endoscopic ultrasound (EUS) on T (personal findings). Magnetic Resonance Imaging (MRI) performs even worse when studying early rectal cancers. In the study of early rectal cancers, MRI has the unique role in determining the possible $\mathrm{N}+$ status, with a slight advantage in the sensitivity compared to EUS, nevertheless not overcoming 50\% in many series [27-29]. Things get even worse once an endoscopic removal has been attempted. The possibility to identify the different wall layers correctly becomes hazardous, reducing further reliability. In this scenario, TEM gains importance as a diagnostic tool, even earlier than a possible treatment.

Based on the histology of the TEM specimen, we were able to reserve radical surgery only for neoplasm at high-risk of recurrence for a remnant disease of invasive carcinoma. At the same time, TEM was curative in early malignancies since none of the T1 tumours recurred. Some could argue that the performance of TEM after a complete endoscopic excision could jeopardise oncological results, being even redundant if high-risk features are detected in the endoscopic samples and delaying the execution of radical surgery. [15] In the present study, 25/101 (16.7\%) patients with a previous cancer diagnosis needed a rescue TME, in line with the 
literature [6]. Only 8 underwent radical surgery and 2 RT. In 2 cases, rescue surgery found metastatic lymph nodes though no residual malignant cells were found in the rectal wall. However, our results demonstrate that rescue surgery can be effectively performed after TEM excision. Similarly, repeated unsuccessful attempts at the endoscopic resection of rectal polyps could delay appropriate staging and raise the risk of overlooking a residual malignancy.

Our data highlighted an interesting recurrence pattern since no statistical difference in the recurrence rate between complete and incomplete EMR was observed. Notably, we found that $10.2 \%, 5 / 49$ with a previous adenoma diagnosis and macroscopic residual disease, had a locally advanced rectal cancer, and $40 \%$ requiring further surgery. It is possible that the excision of the previous polypectomy scar could have prevented further recurrence.

All the T1 tumours in our series were free of recurrence, avoiding major abdominal surgery, although it would have been mandatory in the unexpected case. As expected, a $40 \%$ recurrence rate was observed in $\mathrm{T} 2$ tumours that did not undergo radical surgery, suggesting that TEM alone could not be considered curative in these patients but has a diagnostic role alone. Radical surgery (TME) was always possible following TEM with no particular difficulty reported by the operators, providing a curative treatment when indicated.

Finally, our data support previously published data in questioning the use of endoscopic resection for rectal lesions over $2 \mathrm{~cm}[12,15,30,31]$. Indeed, in several cases when the initial endoscopic excision was deemed complete, TEM was subsequently indicated due to unexpected findings of either carcinoma or persistent dysplastic tissue in the TEM specimen on histological examination, with dysplastic cells seen in $21 \%$ and malignant cells in $16 \%$.

Based on these findings, endoscopic resection may be an inappropriate treatment modality for large rectal polyps, not only for staging but also as an excisional technique due to the possibility of unexpected malignancy. As expected, a statistical significance in lesion size before endoscopic removal was observed between complete and incomplete EMRs, suggesting that larger size could be an independent factor support TEM as the primary treatment modality for such rectal polyps. [27] No risk factor for locally advanced rectal cancer recurrence was statistically significant in our series, probably due to the small number of cases. However, size before EMR demonstrated a risk factor for recurrence in both univariate and multivariate analyses. Therefore, in our opinion, a rate of almost $30 \%$ residual malignant cells justifies performing a completion TEM, despite the $50 \%$ rate of negative histological findings.

In conclusion, TEM represents an appropriate alternative treatment modality to repeated endoscopic excision and offers therapeutic completion in incomplete treatment with endoscopic therapy. Although minimally invasive, this study confirms that TEM avoids radical surgery in the majority of patients with suspected residual disease following endoscopic excision, which in turn facilitates organ preservation and improves patient quality of life in the majority of cases.

Funding Open access funding provided by Marche Polytechnic University within the CRUI-CARE Agreement.

\section{Declarations}

Disclosures Monica Ortenzi, Alberto Arezzo, Roberto Ghiselli, Marco Ettore Allaix, Mario Guerrieri and Mario Morino have no conflicts of interest or financial ties to disclose.

Open Access This article is licensed under a Creative Commons Attribution 4.0 International License, which permits use, sharing, adaptation, distribution and reproduction in any medium or format, as long as you give appropriate credit to the original author(s) and the source, provide a link to the Creative Commons licence, and indicate if changes were made. The images or other third party material in this article are included in the article's Creative Commons licence, unless indicated otherwise in a credit line to the material. If material is not included in the article's Creative Commons licence and your intended use is not permitted by statutory regulation or exceeds the permitted use, you will need to obtain permission directly from the copyright holder. To view a copy of this licence, visit http://creativecommons.org/licenses/by/4.0/.

\section{References}

1. Buchbjerg T, Kroijer R, Al-Najami I, Hansen KU, Baatrup G (2018) Increased rate of incidental colorectal malignant polyps: a single-center experience. Surg Res Pract 2018:3465931

2. Keum N, Giovannucci E (2019) Global burden of colorectal cancer: emerging trends, risk factors and prevention strategies. Nat Rev Gastroenterol Hepatol 16(12):713-732. https://doi.org/10. 1038/s41575-019-0189-8

3. Glynne-Jones R, Wyrwicz L, Tiret E, Brown G, Rödel C, Cervantes A, Arnold D, ESMO Guidelines Committee (2017) Rectal cancer: ESMO clinical practice guidelines for diagnosis, treatment and follow-up. Ann Oncol 28(suppl 4):iv22-iv40. https://doi.org/ 10.1093/annonc/mdx224

4. Buess G, Theiss R, Hutterer F, Pichlmaier H, Pelz C, Holfeld T, Said S, Isselhard W (1983) Die transanale endoskopische Rektumoperation-Erprobung einer neuen Methode im Tierversuch [Transanal endoscopic surgery of the rectum-testing a new method in animal experiments]. Leber Magen Darm 13(2):73-77 (in German)

5. Morino M, Arezzo A, Allaix ME (2013) Transanal endoscopic microsurgery. Tech Coloproctol 17:S55-S61

6. Morino M, Allaix ME, Caldart M, Scozzari G, Arezzo A (2011) Risk factors for recurrence after transanal endoscopic microsurgery for rectal malignant neoplasm. Surg Endosc 25(11):36833690. https://doi.org/10.1007/s00464-011-1777-z

7. Allaix ME, Arezzo A, Morino M (2016) Transanal endoscopic microsurgery for rectal cancer: T1 and beyond? An evidencebased review. Surg Endosc 30(11):4841-4852. https://doi.org/ 10.1007/s00464-016-4818-9 
8. Ferlitsch M et al (2017) Colorectal polypectomy and endoscopic mucosal resection (EMR): European Society of Gastrointestinal Endoscopy (ESGE) Clinical Guideline. Endoscopy

9. Rutter MD et al (2015) British Society of Gastroenterology/Association of Coloproctologists of Great Britain and Ireland guidelines for the management of large non-pedunculated colorectal polyps. Gut 64(12):1847-1873

10. Hashiguchi Y, Muro K, Saito Y, Japanese Society for Cancer of the Colon and Rectum et al (2020) Japanese Society for Cancer of the Colon and Rectum (JSCCR) guidelines 2019 for the treatment of colorectal cancer. Int J Clin Oncol 25(1):1-42. https://doi.org/ 10.1007/s10147-019-01485-z

11. Glimelius B et al (2013) Rectal cancer: ESMO Clinical Practice Guidelines for diagnosis, treatment and follow-up. Ann Oncol 24(Suppl 6):vi81-vi88

12. Barendse RM, van den Broek FJ, Dekker E, Bemelman WA, de Graaf EJ, Fockens P, Reitsma JB (2011) Systematic review of endoscopic mucosal resection versus transanal endoscopic microsurgery for large rectal adenomas. Endoscopy 43(11):941-949. https://doi.org/10.1055/s-0030-1256765

13. Arolfo S, Allaix ME, Migliore M, Cravero F, Arezzo A, Morino M (2014) Transanal endoscopic microsurgery after endoscopic resection of malignant rectal polyps: a useful technique for indication to radical treatment. Surg Endosc 28:1136-1140

14. Fajardo A et al (2013) Transanal endoscopic microsurgery after endoscopic resection of early rectal cancer. A requisite step in treatment? Dis Colon Rectum 56(4):e221-e222

15. Junginger T, Goenner U, Hitzler M, Trinh TT, Heintz A, Blettner M, Wollschlaeger D (2017) Long-term results of transanal endoscopic microsurgery after endoscopic polypectomy of malignant rectal adenoma. Tech Coloproctol 21(3):225-232. https://doi.org/ 10.1007/s10151-017-1595-y

16. Serra-Aracil X, Pallisera-Lloveras A, Mora-Lopez L, Serra-Pla S, Puig-Diví V, Casalots À et al (2018) Transanal endoscopic surgery is effective and safe after endoscopic polypectomy of potentially malignant rectal polyps with questionable margins. Colorectal Dis 20(9):789-796

17. Serra-Aracil X, Gálvez A, Mora-López L, Rebasa P, Serra-Pla S, Pallisera-Lloveras A, Zerpa C, Moreno O, Navarro-Soto S (2018) Endorectal ultrasound in the identification of rectal tumors for transanal endoscopic surgery: factors influencing its accuracy. Surg Endosc 32(6):2831-2838. https://doi.org/10.1007/ s00464-017-5988-9

18. Serra-Aracil X, Caro-Tarrago A, Mora-López L, Casalots A, Rebasa P, Navarro-Soto S (2014) Transanal endoscopic surgery with total wall excision is required with rectal adenomas due to the high frequency of adenocarcinoma. Dis Colon Rectum 57(7):823-829

19. Buess G, Hutterer F, Theiss J, Bobel M, Isselhard W, Pichlmaier H (1984) A system for a transanal endoscopic rectum operation. Chirurg 55:677-680

20. Agha R, Mathew G, STROCSS Group (2021) STROCSS 2021: strengthening the reporting of cohort, cross-sectional and casecontrol studies in surgery. Int J Surg 2021:106165

21. Moss A et al (2011) Endoscopic mucosal resection outcomes and prediction of submucosal cancer from advanced colonic mucosal neoplasia. Gastroenterology 140(7):1909-1918
22. Guerrieri $\mathrm{M}$ et al (2010) treatment of rectal adenomas by transanal endoscopic microsurgery: 15 years' experience. Surg Endosc 24(2):445-449

23. Ramirez JM et al (2009) Local full-thickness excision as first line treatment for sessile rectal adenomas: long-term results. Ann Surg 249(2):225-228

24. Kudo S et al (2008) Nonpolypoid neoplastic lesions of the colorectal mucosa. Gastrointest Endosc 68(4 Suppl):S3-47

25. Bronzwaer MES, Musters GD, Barendse RM, Koens L, de Graaf EJR, Doornebosch PG, Schwartz MP, Consten ECJ, Schoon EJ, de Hingh IHJT, Tanis PJ, Dekker E, Fockens P, TREND study group (2018) The occurrence and characteristics of endoscopically unexpected malignant degeneration in large rectal adenomas. Gastrointest Endosc 87(3):862-871. https://doi.org/10.1016/j.gie. 2017.09.046

26. Lopez A, Bouvier A, Jooste V, Cottet V, Romain G, Faivre J et al (2019) Outcomes following polypectomy for malignant colorectal polyps are similar to those following surgery in the general population. Gut 68(1):111-117

27. Detering $R$, van Oostendorp SE, Meyer VM, van Dieren $S$, Bos ACRK, Dekker JWT, Reerink O, van Waesberghe JHTM, Marijnen CAM, Moons LMG, Beets-Tan RGH, Hompes R, van Westreenen HL, Tanis PJ, Tuynman JB, Dutch ColoRectal Audit Group* (2020) MRI cT1-2 rectal cancer staging accuracy: a population-based study. Br J Surg 107(10):1372-1382

28. Halefoglu AM, Yildirim S, Avlanmis O, Sakiz D, Baykan A (2008) Endorectal ultrasonography versus phased-array magnetic resonance imaging for pre-operative staging of rectal cancer. World J Gastroenterol 14(22):3504-3510. https://doi.org/10.3748/ wjg. 14.3504

29. Al-Sukhni E, Milot L, Fruitman M et al (2012) Diagnostic accuracy of MRI for assessment of T category, lymph node metastases, and circumferential resection margin involvement in patients with rectal cancer: a systematic review and meta-analysis. Ann Surg Oncol 19(7):2212-2223

30. Ueno H, Mochizuki H, Hashiguchi Y, Shimazaki H, Aida S, Hase K, Matsukuma S, Kanai T, Kurihara H, Ozawa K, Yoshimura $\mathrm{K}$, Bekku S (2004) Risk factors for an adverse outcome in early invasive colorectal carcinoma. Gastroenterology 127(2):385-394. https://doi.org/10.1053/j.gastro.2004.04.022

31. Ferlitsch M, Moss A, Hassan C, Bhandari P, Dumonceau JM, Paspatis G, Jover R, Langner C, Bronzwaer M, Nalankilli K, Fockens P, Hazzan R, Gralnek IM, Gschwantler M, Waldmann E, Jeschek P, Penz D, Heresbach D, Moons L, Lemmers A, Paraskeva K, Pohl J, Ponchon T, Regula J, Repici A, Rutter MD, Burgess NG, Bourke MJ (2017) Colorectal polypectomy and endoscopic mucosal resection (EMR): European Society of Gastrointestinal Endoscopy (ESGE) Clinical Guideline. Endoscopy 49(3):270 297. https://doi.org/10.1055/s-0043-102569

Publisher's Note Springer Nature remains neutral with regard to jurisdictional claims in published maps and institutional affiliations. 